\title{
KERUNTUHAN BIROKRASI TRADISIONAL DI KASUNANAN SURAKARTA
}

\author{
THE FALL OF TRADITIONAL BUREAUCRACY \\ OF KASUNANAN SURAKARTA
}

\author{
Muhammad Anggie Farizqi Prasadana \\ Alumnus Program Pascasarjana S2 Ilmu Sejarah UGM \\ Keyongan, RT.5, Karangwaru, Plupuh, Sragen \\ anggie_farizqi@yahoo.com \\ Hendri Gunawan \\ Balai Pelestarian Nilai Budaya Sulawesi Utara \\ Jln. Katamso, Bumi Beringin Lingkungan V \\ hendrygunawan2010@yahoo.com
}

Diterima tanggal 2 Januari 2019

Disetujui tanggal 15 Mei 2019

\begin{abstract}
Kasunanan Surakarta was one of the semi-autonomous kingdoms that had the right of the Dutch to regulate its own bureaucracy. Its bureaucracy was traditional bureaucracy. The authority of the colonial government grew stronger, especially after the Java War, which put the bureaucracy under the colonial bureaucracy. When Indonesia gained independence, the traditional bureaucracy in Kasunanan was destroyed and replaced by a modern bureaucracy. This study aimed to explain the process of the collapse of traditional bureaucracy in Kasunanan Surakarta. This study used a historical method by conducting the source collection (heuristics), source criticism and source interpretation, and finally writing the results. The results showed that the collapse of the traditional bureaucracy in Kasunanan Surakarta was caused by the demands of anti self-governing community who regarded the kingdom as the Dutch accomplice and Sunan's indifference to the ongoing revolutionary movement. The collapse coincided with the omission of special status from Surakarta region. After collapsed, the Republic of Indonesia formed a modern bureaucracy in Surakarta area which placed under the province of Central Java.
\end{abstract}

Keywords: traditional bureaucracy, colonial bureaucracy, and Kasunanan Surakarta.

\begin{abstract}
ABSTRAK
Kasunanan Surakarta merupakan salah satu kerajaan semi-otonom yang diberi hak oleh Belanda untuk mengatur birokrasinya sendiri, yakni birokrasi tradisional. Kekuasaan pemerintah kolonial yang kian menguat, terutama selepas Perang Jawa, menjadikan birokrasi itu berkedudukan di bawah birokrasi kolonial. Ketika Indonesia merdeka, birokrasi tradisional di Kasunanan hancur dan digantikan oleh birokrasi modern. Penelitian ini bertujuan untuk menjelaskan proses keruntuhan birokrasi tradisional di Kasunanan Surakarta. Penelitian ini menggunakan metode sejarah yang dimulai dari pengumpulan
\end{abstract}


sumber (heuristik), melakukan kritik sumber, interpretasi sumber, dan yang terakhir menuliskan hasilnya. Hasil penelitian menunjukkan bahwa keruntuhan birokrasi tradisional di Kasunan Surakarta disebabkan oleh tuntutan yang disuarakan kalangan anti-swapraja yang menganggap kerajaan yang sedang menggema. Keruntuhannya sejalan dengan hilangnya status istimewa yang sempat dikenakan wilayah Surakarta. Setelah runtuh, pemerintah Republik Indonesia membentuk birokrasi modern di daerah Surakarta dan menempatkannya di bawah Provinsi Jawa Tengah.

Kata kunci: birokrasi tradisional, birokrasi kolonial, dan Kasunanan Surakarta.

\section{A. PENDAHULUAN}

Kasunanan Surakarta merupakan wilayah swapraja ${ }^{1}$ pecahan Kerajaan Mataram yang paling senior. Pembentukannya dilakukan pada tahun 1757 dalam Perjanjian Giyanti yang isinya membagi Kerajaan Mataram menjadi dua bagian, Kasunanan Surakarta dan Kasultanan Yogyakarta. Dua tahun kemudian, melalui Perjanjian Salatiga, wilayah Kasunanan dikurangi untuk diberikan kepada Raden Mas Said yang memerintah kerajaan independen yang bernama Kadipaten Mangkunegaran.

Sebagai wilayah swapraja, Kasunanan Surakarta diberi hak oleh Belanda untuk mengatur birokrasi kerajaannya sendiri (Suwarno, 1989: 33). Kendati diberi kebebasan, Belanda tetap melakukan pengawasan secara tidak langsung (indirect rule) terhadap Kasunanan dengan cara menempatkan birokrasi kerajaan di bawah kekuasaan dan pengaruh birokrasi kolonial. Tujuannya agar Belanda mudah

1 Swapraja adalah daerah yang diberi wewenang untuk menjalankan pemerintahannya sendiri. memerintah rakyat Kasunanan (Pranoto, 2001: 58). Selain itu, pengawasan diperlukan untuk mengantisipasi terjadinya pemberontakan dari pihak kerajaan.

Birokrasi di Kasunanan Surakarta ini, menurut Weber, termasuk birokrasi tradisional. Birokrasi tradisional itu kemudian berada di bawah birokrasi modern yang lebih rasional setelah Kasunanan itu sepenuhnya takluk pada Belanda selepas Perang Jawa. Birokrasi modern menurut Weber bercirikan antara lain pengangkatan pejabat yang didasarkan atas kualifikasi profesional, misalnya menggunakan ijazah hasil ujian (Albrow, 2005: 44). Birokrasi modern menurut Weber ini tentu saja sangat berbeda dengan birokrasi tradisional yang selama ini ada di Kasunanan Surakarta. Birokrasi tradisional menerapkan pengangkatan pejabat kerajaan bukan berdasarkan kualitas, melainkan berdasarkan kedekatan dengan raja.

Setelah Indonesia merdeka pada 1945, birokrasi tradisional Kasunanan Surakarta runtuh dan digantikan oleh birokrasi modern yang dibentuk oleh Pemerintah Republik Indonesia. Kini, wilayah Kasunanan masuk ke dalam 
wilayah Jawa Tengah dan sekarang Kasunanan tidak memiliki kekuasaan politik atas wilayahnya. Mereka diberi wewenang sebatas pengembangan kebudayaan Jawa.

Menarik untuk meneliti penyebab keruntuhan birokrasi tradisional di Surakarta yang telah berusia ratusan tahun. Padahal, pada periode sebelum Perang Jawa kerajaan ini begitu digdaya di tanah Jawa dengan birokrasi tradisionalnya. Lantas, pertanyaan dalam penelitian ini adalah bagaimana perkembangan birokrasi tradisional dan kolonial di Surakarta? Mengapa birokrasi tradisional Kasunanan Surakarta bisa runtuh?

Kajian ini meneliti Kasunanan Surakarta dari aspek birokrasi. Salah satu studi mengenai Kasunanan Surakarta adalah sebuah buku karya Darsiti Soeratman yang berjudul Kehidupan Dunia Keraton. Dalam buku itu diulas bagaimana kehidupan para penghuni keraton, simbol-simbol yang digunakan sebagai penanda status sosial kalangan bangsawan, dan kebudayaan-kebudayaan yang dikembangkannya. Namun, studi ini tidak menaruh perhatian terhadap struktur birokrasi yang berlaku di keraton.

Penelitian lain yang mengkaji Kasunanan Surakarta adalah tulisan Dwi Ratna Nurhajarini, Tugas Triwahyono, dan Restu Gunawan (Nurhajarini dkk., 1999). Karangan itu mengulas Kasunanan Surakarta dengan durasi waktu yang amat panjang, sejak pertengahan abad ke-17 hingga awal abad ke-20. Penelitian ini mengkaji kerajaan swapraja itu dari berbagai aspek, antara lain sistem pemerintahan, institusi peradilan, ekonomi, kebudayaan, pendidikan, dan stratifikasi sosial.

Setelah meninjau kelebihan dan kekurangan dua tulisan di atas, maka artikel ini bermaksud untuk memberikan perspektif yang lebih luas. Tulisan ini berupaya untuk menjelaskan perkembangan birokrasi di Kasunanan Surakarta sejak awal berdirinya hingga keruntuhannya pada paruh kedua warsa 1940-an.

\section{B. METODE}

Menurut Kuntowijoyo (2013: 69-82) metode sejarah terdiri atas lima tahap, yaitu: (1) pemilihan topik, (2) pengumpulan sumber, (3) verifikasi (kritik sejarah, keabsahan sumber), (4) interpretasi, dan (5) penulisan. Topik dalam penelitian ini adalah Keruntuhan Birokrasi Tradisional di Kasunanan Surakarta. Untuk memahami keruntuhannya, maka dipakailah sumber primer dan sekunder yang relevan. Sumber primer yang amat berharga adalah tulisan berjudul Vorstenlanden karya G.P. Rouffaer yang diperoleh dari Perpustakaan Pusat Universitas Gadjah Mada (UGM). Sementara sumber-sumber sekunder diperoleh dari Perpustakaan Pusat UGM, Perpustakaan Fakultas Ilmu Budaya UGM, dan Perpustakaan Universitas Negeri Sebelas Maret (UNS). 
Handep, Vol. 2, No. 2, Juni 2019

Tahap berikutnya adalah melakukan kritik sumber baik ekstern maupun intern. Kritik ekstern yang dilakukan menunjukkan bahwa sumber primer yang digunakan autentik dan dipastikan sezaman. Selanjutnya kritik intern memperlihatkan bahwa dokumen-dokumen yang digunakan dalam penelitian ini kredibel.

Setelah kritik atas sumber dokumen dikerjakan, langkah ketiga adalah interpretasi. Pada tahap ini, setiap fakta dicari hubungan kausalitasnya sesuai dengan urutan terjadinya peristiwa. Semua fakta yang ditemukan kemudian disatukan. Tahap terakhir adalah penulisan sejarah yang disusun secara kronologis.

\section{HASIL DAN BAHASAN}

1. Sejarah Singkat Kasunanan Surakarta

Kasunanan Surakarta lahir akibat Perjanjian Giyanti pada tahun 1755 yang membagi Mataram menjadi dua bagian, yakni Kasunanan Surakarta di bawah kepemimpinan Sunan Paku Buwono III dan Kasultanan Yogyakarta di bawah rajanya yang bergelar Sultan Hamengku Buwono I. Sebelumnya, keraton Surakarta telah berdiri terlebih dahulu pada kurun waktu kekuasaan Paku Buwono II (1726-1749) sebagai pengganti keraton Kartasura yang hancur lantaran serangan orang-orang Cina di bawah panji Raden Mas Garendi (Sunan Kuning) (Nurhajarini dkk., 1999: 12).

Adapun wilayah Kasunanan Surakarta selepas perjanjian Giyanti adalah sebagai berikut: a. Daerah Madiun: Jogorogo, Ponorogo, dan separuh Pacitan;

b. Daerah Kediri: Kediri asli, Blitar, Srengat, Lodoyo, dan Pace;

c. Daerah Surabaya: Wirosobo (Mojoagung);

d. Daerah Rembang: Blora;

e. Daerah Banyumas: Banyumas asli, Pamerden (Banyumas Timur), dan Jayaluhur (Banyumas Barat Laut);

f. Daerah Surakarta: Kedawang (Nurhajarini dkk., 1999: 93-94).

Pasca-Perang Jawa wilayah Kasunanan Surakarta semakin jauh menyusut. Pemerintah Hindia-Belanda mencaplok semua wilayah Kasunanan di atas dan sebagian wilayah Kasultanan Yogyakarta yakni daerah Mancanegara Barat (Bagelen, Banyumas, dan Kedu). Hanya wilayah pusat Mataram yang disisakan untuk kedua kerajaan tersebut. Padahal, pada awalnya wilayah kedua kerajaan itu terhampar luas di sebelah selatan rangkaian gunung yang memanjang di tengah Pulau Jawa dari Gunung Slamet di bagian barat hingga Gunung Kelud di bagian timur (Houben, 2002: 9-10).

Wilayah Kasunanan Surakarta kemudian meliputi 6 kabupaten, yakni Kabupaten Surakarta, Kabupaten Kartasura, Kabupaten Klaten, Kabupaten Sragen, Kabupaten Boyolali, dan Kabupaten Ampel. Daerah Surakarta juga terdiri atas 5 afdeeling bentukan Pemerintah HindiaBelanda yang pada waktu itu berkuasa di atas Kasunanan. Kelima afdeeling itu adalah Afdeeling Sragen, Surakarta, 
Klaten, Boyolali, dan Wonogiri (Kuntowijoyo, 2004: 2).

Kekuasaan seorang raja sangat sentral dalam wilayah kerajaannya. Pusat dunia dan pusat kehidupan masyarakat dianggap termanifestasi dalam diri seorang raja. Dengan demikian, baik buruknya sebuah kerajaan menjadi tanggung jawab raja. Oleh karena itu, dalam struktur birokrasi pemerintahan, raja menempati kedudukan tertinggi. Kemudian disusul kaum bangsawan, kaum priyayi, dan struktur yang paling bawah adalah para pengiring, serta para abdi dalem yang jumlahnya cukup banyak (Soeratman, 2000: 209).

\section{Perkembangan Birokrasi Tradisional di Kasunanan Surakarta}

Birokrasi bertujuan untuk melakukan pengawasan ketat secara berjenjang guna mencegah terjadinya kontra birokrasi yang tidak hanya dibutuhkan oleh pemerintahan kerajaan, tetapi juga bagi pemerintah kolonial, atau bahkan pemerintahan modern sekalipun. Guna menyangga pemerintahan pusat, maka diperlukan birokrasi didukung pengaturan yang kuat (Pranoto, 2001: 2).

Struktur birokrasi tertinggi di Kasunanan ditempati oleh raja yang bergelar Sampeyan Dalem Ingkang Sinuhun Kangjeng Susuhunan Paku Buwana Senapati Ing Alaga Ngabdurahman Sayidin Panatagama Khalifatullah. Gelar itu memosisikan raja sebagai kepala pemerintahan sekaligus sebagai panglima perang dan pemimpin agama. Kedudukan dan kekuasaan raja diperoleh berdasarkan keturunan. Posisi raja tersebut, menurut tradisi istana, berlaku hanya bagi putra laki-laki tertua dari permaisuri atau yang ditunjuk oleh raja sajalah yang berhak menggantikan kedudukan sebagai raja (Nurhajarini dkk., 1999: 109-110).

Raja di Surakarta memiliki kekuasaan yang sangat besar dan pemilik segala sesuatu, baik harta benda maupun manusia yang ada dalam wilayah kekuasaannya. Anggapan semacam ini disebut dengan keagungbinataraan. Kendati memiliki kekuasaan yang begitu besar, raja tidak boleh bertindak sesuka hatinya dalam memerintah kerajaan dan rakyatnya. Konsep keagungbinataraan yang dimiliki oleh seorang raja dirangkai dengan sikap berbudi bawa laksana, ambeg adil paramartha, dan wenang wisesa sangari. Sejumlah konsep tersebut menunjukkan bahwa raja dapat dikatakan baik apabila mampu menyeimbangkan antara kewenangannya dan kewajibannya yang besar (Moedjanto, 1987: 77-78).

G. Moedjanto menyebutkan sejumlah karakteristik yang menandai besarnya kekuasaan seorang raja, sebagai berikut.

a. Luas wilayah kerajaannya;

b. Luas daerah taklukannya;

c. Tingginya kesetiaan para bupati dan punggawa lainnya;

d. Kebesaran dan kemeriahan upacara kerajaan dan banyaknya pusaka yang tampak dalam upacara itu; 
Handep, Vol. 2, No. 2, Juni 2019

e. Besarnya tentara dengan segala jenis perlengkapannya;

f. Kekayaan, gelar-gelar yang disandang, dan kemasyhurannya;

g. Seluruh kekuasaan ada di tangannya, tanpa ada yang menyamai dan menandingi (Moedjanto, 1987: 79$80)$.

Raja berhak mengangkat dan memberhentikan pejabat-pejabat dalam pemerintahan yang dipegangnya. Kewenangan yang dimiliki raja tersebut, menunjukkan bahwa terdapat sistem birokrasi yang berkembang di keraton. Hal ini senada dengan konsep birokrasi yang diperkenalkan Max Weber, yaitu sebagai suatu badan administratif tentang pejabat yang diangkat (Albrow, 2005: 41).

Sunan yang diangkat berdasarkan faktor keturunan jelas mengadopsi tradisi yang telah berkembang sebelumnya, bahkan jauh pada masa kerajaan Hindu-Buddha berkuasa di bumi Nusantara. Oleh Weber, birokrasi semacam ini berpangkal pada otoritas tradisional. Otoritas tersebut mendasari sikap patuh terhadap semua perintah raja karena rasa hormat terhadap pola-pola tatanan lama yang telah mapan (Albrow, 2005: 38). Tradisi yang telah ada sejak zaman dahulu tetap dilestarikan dari generasi ke generasi lantaran telah dianggap sebagai sebuah kemapanan yang tidak ada seorangpun yang boleh mengotak-atiknya.

Selanjutnya, struktur organisasi pemerintahan Kerajaan Surakarta terdiri atas tiga lembaga administrasi pemerintahan sebagaimana dalam skema di bawah ini:

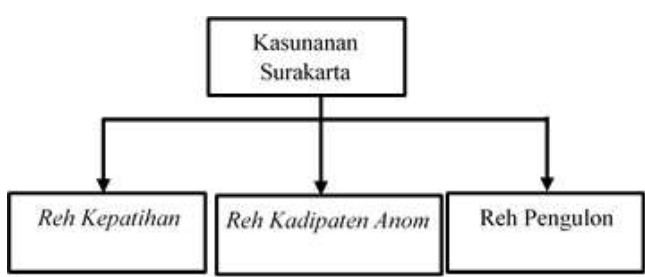

Bagan 1. Struktur Administrasi Pemerintahan Kasunanan Surakarta.

Sumber: diolah dari Rouffaer, 1931: 613614; Nurhajarini dkk., 1999: 111-112.

Fungsi dari 3 lembaga administrasi pemerintahan Surakarta di atas adalah sebagai berikut:

a. Reh Kepatihan adalah lembaga administrasi pemerintahan di bawah kekuasaan patih. Patih berkedudukan sebagai pejabat tertinggi dalam hierarki birokrasi dan berfungsi sebagai wakil sunan dalam bidang pemerintahan. Lembaga ini dalam pelaksanaannya dibantu oleh para bupati yang terdiri atas bupati nayaka (bupati pemerintahan) dan bupati pangreh praja. Bupati nayaka berjumlah delapan orang (nayaka wolu) yang terbagi lagi menjadi empat bupati nayaka lebet dan empat bupati nayaka jawi. Bupati lebet bertugas mengurusi urusan di dalam istana (parentah Keraton). Sementara bupati jawi bertugas menjaga keamanan dan ketentraman kawula dalem di daerah Negara Agung. Bupati pangreh praja menguasai daerah teritorial di tingkat kabupaten; 
b. Reh Kadipaten Anom adalah lembaga yang berada di bawah kekuasaan Pangeran Adipati Anom yang berkedudukan sebagai kepala administrasi dan mengurus kebutuhan para sentana dalem;

c. Reh Pangulon adalah lembaga yang bertugas mengurus administrasi keagamaan yang berada di bawah pimpinan pengulu tafsir anom. Penghulu keraton berfungsi sebagai penasihat raja. Khususnya ketika raja mengambil keputusan hukuman di pengadilan, dalam kedudukannya sebagai anggota lembaga peradilan Surambi (Nurhajarini dkk., 1999: 111-112).

Pada masa pemerintahan Sunan Paku Buwono X, birokrasi pemerintahan di Kasunanan Surakarta mengalami perubahan. Fungsi dari masing-masing institusi itu adalah sebagai berikut.

a. Reh Kasentanan: lembaga ini bertugas melayani raja, permaisuri, serta anak raja;

b. Reh Kanayakan: lembaga ini bertugas melayani para abdi dalem kerajaan;

c. Lembaga yang mengurusi keuangan istana;

d. Lembaga yang mengurusi yayasan, rumah tinggi istana, perlengkapan istana, dan kegiatan istana yang lain. Misalnya, wisudan dan manten;

e. Lembaga yang mengurusi tanah pamijen keraton dan pembangunan di lingkungan istana (Nurhajarini dkk., 1999: 158-159).
Pada kurun waktu kekuasaan Paku Buwono $X$ dibentuk pula Dewan Pertimbangan (raad) yang bertugas mendampingi raja beserta para abdi dalem dalam menjalankan roda pemerintahan kerajaan. Ketiga dewan itu adalah sebagai berikut:

a. Dewan Bale Agung: dewan ini bertugas memberikan pertimbangan dan saran terhadap rancangan peraturan yang hendak dikeluarkan;

b. Dewan Karaton: dewan ini ditujukan khusus untuk kepentingan raja yang bertugas mengajukan usul dan mempertimbangkan hasil keputusan;

c. Dewan Kapatihan: dewan ini bertugas untuk memberi pertimbangan atas segala keputusan Dewan Bale Agung yang telah mendapat peninjauan dari Dewan Karaton (Nurhajarini dkk., 1999: 160-161).

\section{Masuknya Birokrasi Kolonial}

Pengaruh birokrasi kolonial yang paling awal terjadi sejak berakhirnya zaman Kartasura pada 1743. Perubahan terutama tampak dalam jabatan patih. Patih yang semula pimpinan administratif tertinggi dalam birokrasi tradisional menjadi bagian dari birokrasi kolonial. Patih diangkat dan diberhentikan oleh Belanda melalui sebuah kontrak. Selanjutnya, kedudukan patih sejajar dengan kedudukan raja (Soejatno, 1972: 7).

Birokrasi kolonial juga menempatkan seorang residen di wilayah sunan, yang bukan berkedudukan sebagai 
Handep, Vol. 2, No. 2, Juni 2019

perwakilan asing, melainkan sebagai penasihat. Residen menempati kedudukan tertinggi dalam birokrasi kolonial di Surakarta yang dibantu oleh asisten residen di daerah luar keraton. Memasuki akhir abad ke-19, residen menjelma menjadi penguasa tertinggi di Surakarta dengan patih Kasunanan sebagai salah satu pembantunya (Soejatno, 1972: 7-8).

Sejak perjanjian Giyanti tahun 1755, VOC kian berani mencampuri urusan politik internal keraton, terutama pasca-Perang Jawa berkecamuk. Alasan intervensi itu adalah kekhawatiran Belanda akan terjadinya Perang Jawa edisi kedua. Oleh sebab itu, mereka menempatkan seorang residen untuk wilayah Surakarta, sedangkan di tiaptiap daerah yang dikepalai oleh bupati ditempatkan seorang asisten residen. Keberadaan pemerintah kolonial adalah untuk mengawasi keseluruhan jalannya pemerintahan Kasunanan. Struktur pemerintahan kolonial di Surakarta pada masa Pakubuwana $\mathrm{X}$ digambarkan dalam skema berikut:

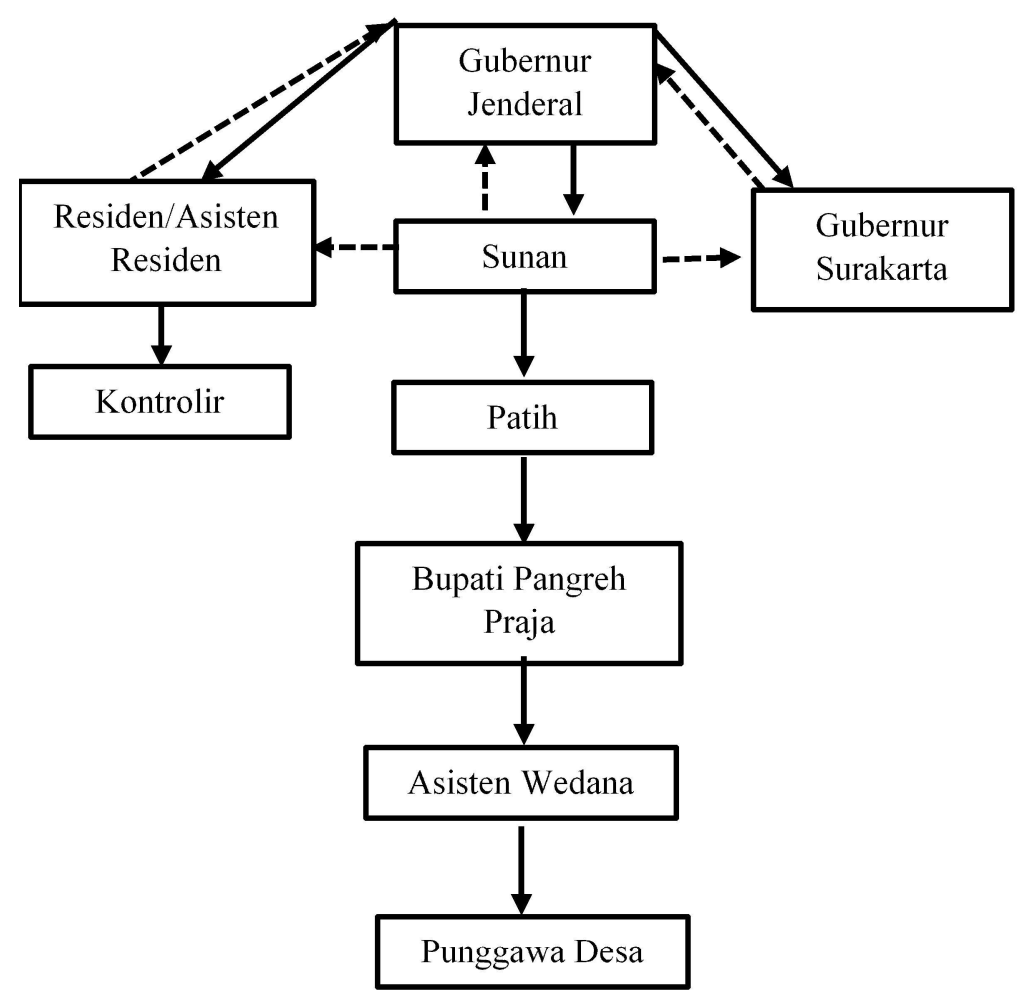

Keterangan:

$\longrightarrow$ : Garis Komando

$\longrightarrow$ : Garis Konsultasi

Bagan 2. Struktur Birokrasi Kolonial di Surakarta.

Sumber: diolah dari Soejatno, 1972: 7-8. 
Dari skema tersebut dapat dijelaskan bahwa sistem pemerintahan Kasunanan Surakarta berada di bawah kekuasaan pemerintah kolonial. Terlihat pula bahwa Belanda tidak menghapuskan birokrasi tradisional yang ada, tetapi mempertahankannya. Belanda sengaja membiarkan birokrasi tersebut tetap eksis lantaran ingin memanfaatkan karisma penguasa tradisional guna menguasai dan mengatur rakyatnya. Dengan begitu, keinginan Belanda dapat dengan mudah tercapai tanpa menimbulkan gejolak perlawanan.

Pada tanggal 17 Agustus 1945 Indonesia memperoleh kemerdekaannya. Segera setelah itu, proklamasi kemerdekaan disiarkan melalui radio Domei Indonesia dan jaringan telegraf. Revolusi Indonesia telah dilancarkan (Kahin, 1995: 172-173). Krisis politik yang berkepanjangan antara Indonesia dan Belanda terjadi selepas bangsa Indonesia memproklamasikan kemerdekaannya. Pemerintah Belanda berupaya menguasai kembali bangsa Indonesia selama rentang waktu 1945 hingga akhir 1949 (Sulistyobudi, 2011: 113).

Realitas historis lain mengungkapkan bahwa pada masa itu mengandung pula permasalahan-permasalahan sosial (Ibrahim, 2004: 5). Suyatno Kartodirdjo menambahkan bahwa bentuk konflik sosial seperti pembunuhan, pencurian, pemberontakan, dan kegelisahan sosial juga terjadi dalam revolusi Indonesia (Kartodirdjo dalam Ibrahim, 2004: 5). Bentuk-bentuk permasalahan sosial yang disebutkan di atas terjadi pula di daerah Surakarta.

George D. Larson menggambarkan periode revolusi di Surakarta sebagai masa pergolakan. Terminologi temporal tersebut muncul karena kota ini merupakan pusat kegiatan komunis, perang antar-kelas, penculikan, dan kekacauan umum yang merembes ke bagian-bagian lain di Jawa dan memengaruhi jalannya revolusi. Sunan sendiri tidak memperlihatkan dukungannya terhadap gerakan revolusi, tidak mengambil tindakan yang progresif, sehingga kehilangan kesetiaan dari rakyatnya (Larson, 1990: 3).

Permasalahan sosial yang muncul di Surakarta bercampur baur dengan gerakan revolusioner yang terjadi di daerah itu. Revolusi sosial di Surakarta merupakan pertemuan antara kebencian rakyat kepada pemimpin-pemimpin tradisional dan kepentingan kekuatan politik yang ingin menggoyang pemimpin-pemimpin nasional. Rakyat sudah lelah lantaran dijajah Belanda, diduduki Jepang, didominasi keraton, serta ketidakpedulian keraton terhadap revolusi (Ibrahim, 2004: 153). Kesemuanya itu melahirkan gerakan swapraja di Surakarta yang nantinya akan mengubah birokrasi tradisional keraton yang telah bertahan berabadabad lamanya dan secara turuntemurun.

Pada tahun 1946, revolusi sosial yang terjadi di Surakarta membuat heboh masyarakat lantaran menculik Sunan dan beberapa pembesar istana. 
Handep, Vol. 2, No. 2, Juni 2019

Alasan penculikan tersebut karena rakyat menghendaki agar Sunan memahami realitas yang terjadi di luar tembok keraton serta menanggalkan hak-hak istimewa yang selama ini mereka miliki guna disejajarkan dengan para pemimpin nasional kala itu. Aksiaksi nekat yang ditujukan pada keraton menyebabkan kedudukan keraton kian lemah dan menguatkan gerakan antiswapraja di tengah-tengah masyarakat (Ibrahim, 2004: 157).

Keadaan darurat di Surakarta memuncak kala Sutan Syahrir diculik oleh kaum oposisi republik pimpinan Tan Malaka. Setelah dilakukan penculikan, segelintir pasukan oposisi berupaya menyerang istana presiden di Yogyakarta, tetapi berhasil digagalkan. Semenjak kejadian yang berbahaya itu, demi memulihkan situasi yang kian genting, pemerintah akhirnya mengabulkan keinginan kelompok oposisi untuk membubarkan daerah swapraja Surakarta melalui Peraturan Presiden 15 Juli No. 16/SD/1946. Dengan peraturan tersebut, maka kekuasaan Kasunanan Surakarta secara de facto dan de jure telah runtuh (Ibrahim, 2004: 165-166).

Pasca-runtuhnya Kasunanan Surakarta, birokrasi modern mulai diperkenalkan di wilayah ini dengan dibentuknya Komite Nasional Daerah (KND) pada September 1945. Raden Pandji Suroso menjadi Komisaris Tinggi Pemerintah RI yang berkedudukan di Kota Surakarta. Atas usul Badan Pekerja KND, Komisaris Tinggi menyetujui dibentuknya
Pemerintahan Direktorium untuk daerah Surakarta. Pemerintahan ini diketuai oleh Komisaris Tinggi dan mempunyai 9 anggota, yaitu 5 dari KND dan 4 merupakan wakil-wakil yang ditunjuk oleh Sri Paku Buwono dan Mangkunagoro (Huda, 2013: 412).

Sejak pembentukan Komisaris Tinggi yang berkuasa di seluruh daerah Surakarta (Kasunanan dan Mangkunegaran) pada hakikatnya sudah bukan lagi Sri Sunan dan Sri Mangkunegoro atau Pepatih Dalemnya masing-masing melainkan sejak saat itu yang memegang kekuasaan tidak lain adalah Komisaris Tinggi RI bersama-sama Komite Nasional Indonesia sebagai wakil rakyat dan sehari-hari Direktorium tersebut. Semua kabupaten dalam kedua daerah tersebut pada akhirnya satu persatu memisahkan diri dari Kasunanan Surakarta dan daerah Mangkunegaran dan menggabungkan diri ke dalam Republik Indonesia langsung di bawah pimpinan Komisaris Tinggi sebagai wakil Republik Indonesia yang sah (Huda, 2013: 412).

Dengan demikian, sejatinya birokrasi tradisional yang terdapat di Surakarta telah runtuh. Selepas itu, pemerintah Indonesia kembali memperkenalkan birokrasi modern di Surakarta dengan membentuk Haminte Kota Surakarta. Tujuan pembentukan tersebut adalah sebagai pemerintah daerah pendahuluan sebelum menetapkan bentuk dan susunan pemerintahan daerah yang berdasarkan kedaulatan rakyat (demokrasi) untuk 
seluruh daerah Republik Indonesia.

Daerah Haminte Surakarta meliputi:

a. Sebagian dari kabupaten-kota, Kasunanan, dan sebagian dari kabupaten-kota Mangkunegaran, yang batasnya ditetapkan dalam surat ketetapan Pemerintah HindiaBelanda, termuat di dalam Bijblad, No. 13318;

b. Kalurahan Nusukan yang dimaksudkan dalam surat Ketetapan Pemerintah Mangkunegaran tanggal 25 November 1942, No. 186;

c. Kalurahan-kalurahan Karangasem, Kerten, Jajar, Sumber, dan Banyuanyar yang seluruhnya dari Onderdistrik Colomadu, Kabupaten Karanganyar;

d. Kelurahan-kelurahan Kadipiro dan Mojomengo dari Onderdistrik Gondangrejo, Kabupaten Karanganyar, ditunjuk sebagai daerah yang berhak mengatur dan mengurus rumah tangganya sendiri. ${ }^{2}$

Pemerintah Haminte-Kota terdiri atas:

a. Dewan Perwakilan Rakyat HaminteKota atau disingkat: Dewan Kota;

b. Dewan Executief Haminte-Kota atau disingkat Dewan Pemerintah Kota; c. Wali Kota.

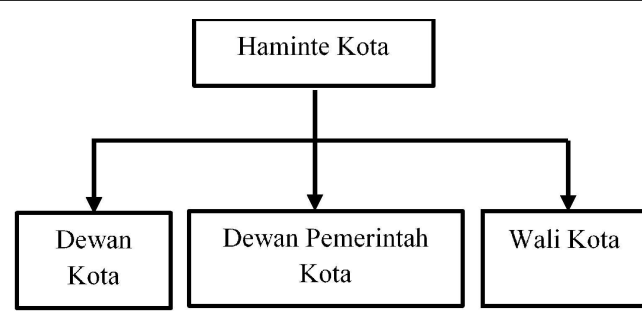

Bagan 3. Struktur Pemerintah Haminte Kota Surakarta.

Sumber: UU No. 16 Tahun 1947 tentang Pembentukan Haminte-Kota Surakarta, http:/ /jdih.ristekdikti.go.id/?q=system/files/ perundangan/11777399.pdf, diakses $30 \mathrm{Mei}$ 2017.

Dewan Kota terdiri atas:

a. Wali kota sebagai ketua;

b. Seorang wakil ketua merangkap wakil wali kota yang dipilih oleh dan dari anggota-anggota Dewan Kota;

c. Lima puluh anggota yang dipilih oleh penduduk haminte-kota menurut undang-undang pemilihan.

Dewan Pemerintah Kota yang menjalankan pemerintahan hamintekota sehari-hari terdiri atas:

a. Wali kota sebagai ketua merangkap anggota;

b. Wakil ketua (anggota) merangkap wakil ketua Dewan Kota;

c. Lima anggota yang dipilih oleh dan dari anggota Dewan Kota. ${ }^{3}$

Tidak cukup sampai disitu, lantaran kekacauan yang berlarut-larut di wilayah Surakarta, maka dibentuklah pemerintahan darurat militer di bawah Gatot Subroto pada tahun 1947. Adapun

\footnotetext{
${ }^{3}$ UU No. 16 Tahun 1947 tentang Pembentukan Haminte-Kota Surakarta, http://jdih. ristekdikti.go.id/?q=system/files/ p\%20erundangan/11777399.pdf, diakses pada 30 Mei 2017.
} 
Handep, Vol. 2, No. 2, Juni 2019

struktur birokrasi pada periode itu adalah sebagai berikut.

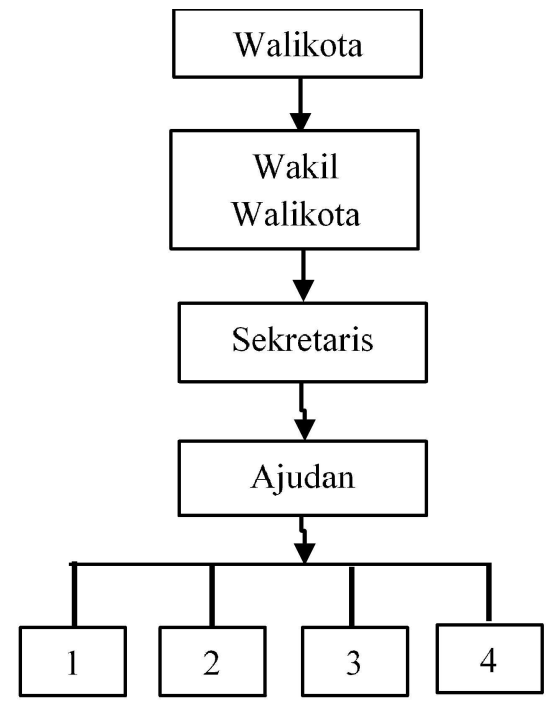

Keterangan:

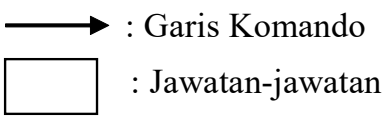

Bagan 4. Struktur Birokrasi Pemerintah Darurat Militer 1947.

Sumber: Rosiana, 2013: 105.

\section{SIMPULAN}

Semula Kasunanan Surakarta menggunakan birokrasi tradisional. Raja menjadi pemegang otoritas tertinggi di kerajaan sekaligus sebagai panglima perang, pemimpin agama, dan hakim bagi rakyatnya. Kekuasaan raja yang begitu besar juga terlihat dalam pengangkatan dan pemberhentian para pejabatnya yang didasarkan atas faktor keturunan, sedangkan sisi kualitas nomor dua. Semakin para pejabat dekat dengan raja, kian tinggi pula kedudukannya.

Pasca-Perang Jawa (Perang Diponegoro) pada tahun 1830, birokrasi tradisional mulai terusik. Belanda datang dengan birokrasi modernnya. Raja sekarang bukan lagi penguasa tertinggi di kerajaannya. Ia berada di bawah kekuasaan residen dan tentu saja Gubernur Jenderal. Sekarang, tidak semua pejabat diangkat oleh raja sendiri. Sebagai contoh, jabatan patih diangkat sendiri oleh Belanda dengan sebuah kontrak. Oleh sebab itu, tidak heran apabila patih lebih loyal kepada Belanda. Dalam mengangkat dan memberhentikan pejabat di Kasunanan, Belanda lebih mementingkan kualitas, tidak lagi berdasarkan keturunan. Kendati demikian, tidak dapat dipungkiri bahwa kepentingan Belanda untuk mencari bawahan yang loyal kepadanya menjadi penentu dominan dalam pengangkatan dan pemberhentian pejabat di keraton.

Pada periode kemerdekaan, timbullah gerakan anti-swapraja dari para pejuang Indonesia yang meruntuhkan kekuasaan keraton beserta birokrasinya. Mereka memandang birokrasi tradisional amat feodal dan bertentangan dengan semangat nasionalisme yang sedang menyalanyala. Akibatnya, segala kekuasaan dan hak istimewa yang dimiliki keraton runtuh di tangan kaum republik. Keraton kemudian hanya menjadi perawat budaya Jawa dan ditempatkan di bawah wilayah administratif Provinsi Jawa Tengah. 


\section{DAFTAR SUMBER}

Albrow, Martin. 2005. Birokrasi. Yogyakarta: Tiara Wacana.

Houben, Vincent J. H. 2002. Keraton dan Kompeni: Surakarta dan Yogyakarta 1830-1870. Terjemahan. E. Setiyawati Alkhatab. Yogyakarta: Bentang Budaya.

Huda, Ni’matul. 2013. Pengakuan Kembali Surakarta Sebagai Daerah Istimewa Dalam Perspektif Historis dan Yuridis. Jurnal Hukum Ius Quia Iustum No. 3 Vol. 20, hlm. 402-422.

Ibrahim, Julianto. 2004. Bandit dan Pejuang di Simpang Bengawan: Kriminalitas dan Kekerasan Masa Revolusi di Surakarta. Wonogiri: Bina Citra Pustaka.

Kahin, George McTurnan. 1995. Refleksi Pergumulan Lahirnya Republik: Nasionalisme dan Revolusi di Indonesia. Terjemahan. Nin Bakdi Soemanto. Surakarta: UNS Press.

Kartodirdjo, Sartono. 1977. "Metode Penggunaan Bahan Dokumenter", dalam Koentjaraningrat (ed), Metode-Metode Penelitian Masyarakat. Jakarta: Gramedia.

Kuntowijoyo. 2004. Raja, Priyayi, dan Kawula: Surakarta, 19001915. Yogyakarta: Ombak. 2013. Pengantar Ilmu Sejarah. Yogyakarta: Tiara Wacana.
Larson, George D. 1990. Masa Menjelang Revolusi: Keraton dan Kehidupan Politik di Surakarta 1912-1942. Yogyakarta: UGM Press.

Moedjanto, G. 1987. Konsep Kekuasaan Jawa: Penerapannya oleh Raja-Raja Mataram. Yogyakarta: Kanisius.

Nurhajarini, Dwi Ratna, Tugas Triwahyono, dan Restu Gunawan. 1999. Sejarah Kerajaan Tradisional Surakarta. Jakarta: Depdikbud.

Pranoto, Suhartono W. 2001. Serpihan Budaya Feodal. Yogyakarta: Agastya Media.

Rosiana, Belda Ranika. 2013. Terbentuknya Birokrasi Modern di Surakarta Tahun 1945-1950. Skripsi. Surakarta: Program Studi Ilmu Sejarah UNS.

Rouffaer, G.P. 1931. Vorstenlanden. 'sGravenhage: Martinus Nijhoff.

Soejatno. 1972. Kolonialisme Barat dan Kemunduran Radja-Radja Surakarta Abad 19. Surakarta: IKIP Surakarta.

Soeratman, Darsiti. 2000. Kehidupan Dunia Keraton Surakarta 18301939. Yogyakarta: Yayasan untuk Indonesia.

Sulistyobudi, Langgeng. 2011. Revolusi dan Masalah Kemanusiaan di Surakarta dan Yogyakarta, dalam 
Agus Suwignyo, dkk. (ed.).

Sejarah Sosial (di) Indonesia:

Perkembangan dan Kekuatan.

Yogyakarta: Jurusan Sejarah FIB

UGM.

Suwarno, P.J. 1989. Sejarah Birokrasi

Pemerintahan Indonesia Dahulu

dan Sekarang. Yogyakarta:

Penerbitan Universitas Atma Jaya

Yogyakarta.

UU No. 16 Tahun 1947 tentang

Pembentukan Haminte-Kota

Surakarta, diunduh dari http://

jdih.ristekdikti.go.id/?q= system/ files/perundangan/1177 7399.pdf, pada 30 Mei 2017. 